\title{
Iron consumption in obese pregnant women and birth outcome
}

\author{
J. C. Abayomi ${ }^{1}$, M. Charnley ${ }^{1}$, L. D. Richardson ${ }^{1}$ and A. Weeks ${ }^{2}$ \\ ${ }^{1}$ Faculty of Education, Community and Leisure, Liverpool John Moores University, IM Marsh Campus, Barkhill Road, \\ Liverpool L17 6BD and ${ }^{2}$ Liverpool Women's Hospital, Crown Street, Liverpool L8 7SS, UK
}

Low BMI and iron deficiency anaemia in pregnancy are associated with increased risk of pre-term delivery (PTD) and low birth weight $(\mathrm{LBW})^{(1,2)}$. The National Diet and Nutrition Survey (2010) found that iron intakes fell below the lower reference nutrient intake (LRNI) in $20 \%$ of adult women ${ }^{(3)}$. Other studies show that $80 \%$ of pregnant women achieve intakes less than the reference nutrient intake (RNI) for iron $^{(3)}$. The aim of this study was to explore the dietary intake of obese pregnant women in relation to LBW and PTD. Women were recruited from antenatal clinic and asked to complete three-day food diaries during each trimester of pregnancy. Data regarding food portion size was verified using a food atlas ${ }^{(4)}$ and the diaries were then analysed using Microdiet ${ }^{(i}$. Following delivery comparisons were made between dietary data and birth outcome data routinely recorded at delivery by the hospital. Data were collected for 139 pregnant women with a BMI $\geq 35 \mathrm{~kg} / \mathrm{m}^{2}$. Mean booking-in weight was $110 \mathrm{~kg}$ (SD 15.5).

\begin{tabular}{|c|c|c|c|c|}
\hline Iron Intake mg & & $<$ RNI $(\%)$ & $<\operatorname{EAR}(\%)$ & < LRNI (\%) \\
\hline $\mathbf{1}^{\text {st }}$ trimester $^{\mathrm{A}}$ & 10.64 (SD 4.33) & 86.0 & 68.8 & 29.0 \\
\hline $2^{\text {nd }}$ trimester $^{B}$ & $10.55(\mathrm{sD} 3.74)$ & 89.9 & 67.7 & 23.2 \\
\hline $3^{\text {rd }}$ trimester $^{C}$ & 11.63 (SD 3.85) & 81.9 & 54.2 & 15.3 \\
\hline Mean & 10.94 (SD 3.97) & 85.9 & 63.6 & 22.5 \\
\hline
\end{tabular}

Mean energy intakes at each trimester were similar to the estimated average requirement (EAR) of $1940-2140 \mathrm{kcal} / \mathrm{d}^{(5)}(1849 \mathrm{kcal} / \mathrm{d}$; $1984 \mathrm{kcal} / \mathrm{d} ; 2066 \mathrm{kcal} / \mathrm{d}$ respectively). Overall iron intakes were low with $63.6 \%$ achieving $<$ EAR and $22.5 \%$ achieving < LRNI (table 1 ). Spearman's correlation test failed to show a significant relationship between iron intake and birth outcome (all $p>0.05$ ) but all 6 women with a LBW baby $(<2.5 \mathrm{~kg}$ ) and 7 out of 8 women with pre-term delivery ( $<37$ weeks) failed to achieve RNI for iron. The results suggest that despite a high BMI and an adequate energy intake, quality of diet may be lacking in obese pregnant women. This provides further evidence of the association between iron deficiency and LBW and PTD.

1. Scholl TO \& Hediger ML (1994) Anemia and iron-deficiency anemia: compilation of data on pregnancy outcome. Am J Clin Nutr 59, 492S-500S.

2. Johnson JWC \& Yancy MK. (1996) A Critique of the New Recommendations for Weight Gain in Pregnancy. American Journal of Obstetrics and Gynecology 174(1): 254-258.

3. National Diet and Nutrition Survey (2010) Available at: http://www.food.gov.uk/multimedia/pdfs/publication/ndnsreport0809.pdf. (Accessed 28/04/12)

4. Alwan N, Greenwood DC, Simpson NAB, McArdle HJ, Godfrey KM and Cade JE. (2011) Dietary iron intake during early pregnancy \& birth outcomes in a cohort of British women. Hum Reprod 26(4): 911-919.

5. Nelson M, Atkinson M and Meyer J (2002) A photographic atlas of food portion sizes FSA.

6. COMA (1991) Dietary Reference Values for Food, Energy \& Nutrients for the UK. HMSO: London. 